\title{
KONSELING DALAM WORKSHOP MENJADI IBU BAHAGIA DALAM MENDIDIK ANAK SAAT PANDEMI DI SEKOLAH DASAR NEGERI CIPASUNG, KUNINGAN
}

\author{
Mia Zultrianti Sari, Eli Hermawati, Myrna Apriani Lestari dan Agus Gunawan \\ Program Studi Pendidikan Guru Sekolah Dasar, Fakultas Keguruan dan Ilmu Pendidikan \\ Universitas Kuningan, Indonesia \\ E-mail : mia.zultrianti.sari@uniku.ac.id
}

\begin{abstract}
Learning during the Covid19 pandemic is certainly not a condition commonly experienced by the Indonesian people, including in Kuningan Regency. This unusual condition, of course, triggers several problems faced by the learning implementers. The problems that often occur during this pandemic are not only for teachers and students, but also for parents at home. Learning with the online method and home visit certainly makes the intensity of togetherness between students and parents at home during school hours to be more than before. Parents' unpreparedness in accompanying children to learn is a problem that tends to emerge during the COVID-19 pandemic. The unpreparedness of the parents to accompany the child to study at home certainly makes the mental condition of the parents less healthy and will also affect the mental condition of the child. Children do not find comfort and motivation to learn.
\end{abstract}

Keywords: Parents, Learning, Covid pandemic 19.

\begin{abstract}
Abstrak
Pembelajaran di masa pandemi covid19 tentu bukan kondisi yang biasa dialami oleh masyarkat Indonesia termasuk di Kabupaten Kuningan. Kondisi yang tidak biasa dihadapi tersebut tentu memicu adanya beberapa masalah yang dihadapi oleh pelaksana pembelajaran. Masalah yang banyak terjadi saat pandemi ini bukan hanya dari guru dan siswa, tapi juga terjadi pada orang tua siswa di rumah. Pembelajaran dengan metode daring dan home visit tentu menjadikan intensitas kebersamaan siswa dan orang tua dirumah pada jam sekolah menjadi lebih banyak dibanding sebelumnya. Ketidaksiapan orang tua dalam mendampingi anak belajar merupakan masalah yang cendrung muncul di masa pandemi covid19 ini. Ketidaksiapan orang tua mendampingi anak belajar dirumah tentu membuat kondisi mental orang tua kurang sehat dan akan mempengaruhi juga kepada kondisi mental anak. Anak tidak menemukan kenyaman dan motivasi untuk belajar.
\end{abstract}

Kata Kunci : Orang Tua, Pembelajaran, Pandemi covid19

\section{PENDAHULUAN}

Globalisasi dimana semua aspek kesadaran dan kesempatan semakin meningkat. Hakekat pembangunan nasional adalah peningkatan kesejahteraan masyarakat yang mencerminkan kualitas hidup dari suatu keluarga, dimana keluarga yang memiliki kualitas hidup yang lebih baik umumnya memiliki tingkat kesejahteraan yang lebih baik juga (Rosni, 2017). Keluarga merupakan suatu unit terkecil yang terdiri atas ayah, ibu, anak. Keluarga berfungsi dalam bertanggungjawab untuk menjaga, menumbuhkan dan mengembangkan anggota keluarga (Telaumbanua \& Nugraheni, 2018). Orang tua yang tidak siap cendrung akan lebih mudah untuk marah dan tidak sabar dalam mengajari anaknya. Padahal rasa aman adalah kondisi yang sangat mendasar yang diperlukan oleh siswa dalam memulai pembelajaran. Seperti yang dikemukakan oleh Desmita (2009: 69) bahwa rasa aman merupakan suatu kebutuhan yang sangat penting bagi kehidupan peserta 
didik, terutama rasa aman di dalam kelas dan Sekolah. Dalam kondisi pandemi covid 19 ini tentu kondisi aman tidak akan didapatkan di sekolah dan di dalam kelas, sehingga tugas orang tua lah yang harus mengkondisikan sedemikian rupa akan perasaan aman siswa dan menjamin pembelajaran akan terlaksana dengan baik walau tidak di sekolah (Rusmiati et al., 2020).

Chaplin 1972 dalam (Syah, 2010: 18) menitikberatkan manfaat psikologi pendidikan untuk memecahkan masalah- masalah yang terdapat dalam dunia pendidiakn dengan cara menggunakan metode-metode yang telah disusun rapi dan sistematis. Entah masalahnya itu dari Guru, Siswa, atau situasi belajar mengajar yang dihadapai guru dan siswa yang bersangkutan. Ada 10 macam kegiatan pendidikan yang banyak memerlukan prinsip- prinsip psikologis, yakni: 1) Seleksi Penerimaan Siswa Baru; 2) Perencanaan Pendidikan; 3) Penyusunan Kurikulum; 4) Penelitian Kependidikan; 5) Adiminitrasi Kependidikan; 6) Pemilihan materi pelajaran; 7) Interaksi Belajar Mengajar; 8) Pelayanan bimbingan dan penyuluhan; 9) Metodologi mengajar; 10) Pengukuran dan Evaluasi (Syah, 2010: 18).

Keahlian tersebut sudah tentu harus dikelola oleh guru. Namun dalam kondisi pandemi covid19 ini hal itu tidak sepenuhnya berlaku. Guru tidak bisa sepenuhnya bisa mendampingi secara langsung dalam proses kegiatan pembelaran. Untuk anak usia SD Transfer ilmu melalui daring, tentu tidak lebih efektif dibanding dengan tatap muka secara langsung di dalam ruangan kelas (Lapada et al., 2020). Tugas guru sedikit beralih kepada orang tua, dikarenakan siswa belajar jarak jauh dari rumah masing-masing didampingi oleh orang tua. Namun yang terjadi dilapangan, beralihnya sedikit tugas guru kepada orang tua tidak disertai dengan penyuluhan dan pendampingan khusus dari pihak sekolah kepada orang tua sehingga orang tua seolah menanggung beban baru sebagai guru dadakan bagi anak-anaknya di rumah (Borup, 2016). Itulah kiranya kenapa banyak orang tua yang mengeluhkan kondisi pembelajaran daring merupakan beban tersendri bagi mereka di saat pandemi covid19 (Purwanto et al., 2019). Beban dan Keluhan inilah yang sering meletup menjadi sebuah energi negatif dan dirilis menjadi sebuah amarah yang meletup dengan intonasi nada yang tinggi kepada anak.

Emosi itu sendiri dapat diartikan sebagai suatu suasana yang kompleks dan getaran jiwa yang menyertai atau muncul sebelum/sesudah terjadinya prilaku (Syamsuddin, 2007: 114). Konsep tentang emosi inilah yang sedikit sekali dipelajari dan diarahkan kepada orang tua siswa, bahkan dalam rapat orang tua dalam awal semester sekalipun. Padahal emosi adalah dasar dari sebuah prilaku setiap individu, baik itu sebagai posisi guru ataupun siswa. Dalam proses belajar mengajar siswa harus menjadi fokus dan objek utama yang harus diperhatikan, termasuk perkembangan emosinya (Trentacosta et al., 2006). Selanjutnya Syamsuddin (2007:115) mengutarakan:

Ada dua dimensi emosional yang sangat penting diketahui para pendidik, terutama para guru. Yang Pertama adalah senang tidak senang atau suka tidak suka. Yang Kedua intensitas kuat-lemah atau halus kasarnya atau dalam dangkalnya emosi tersebut. Hal tersebut diatas sangatlah penting karena dapat memberikan motivasi pengarahan dan integritas perilaku seseorang, disamping mungkin pula akan menjadi sebuah hambatan-hambatan yang bersifat fatal bahkan sampai frustasi. 
Emosi adalah sebuah energi yang kekal. Tidak bisa hilang tapi bisa disalurkan. Emosi negatif dari orang tua akan melemahkan motivasi siswa dalam belajar (Nauli Thaib, 2013). Motivasi yang menurun dikhawatirkan akan berpengaruh terhadap pemahaman materi dan hasil belajar siswa. Sebagai orang dewasa, Guru dan Orang tua harusmya mengerti bahwa sebenarnya anak tidak suka dengan kondisi pandemi covid19 (Kidd \& Murray, 2020). Ketidaksukaan anak, bisa jadi memicu emosi yang dalam dan melemahkan semangat belajar (Silaen \& Dewi, 2015). Disinilah peran penting orang tua dirumah untuk lebih bisa mengendalikan emosi dibanding anak, agar bisa memberikan motivasi, memfasilitasi dan memberikan rasa aman untuk siswa dalam proses belajar secara daring (Buthaina \& Mohamed, 2020). Bahkan Menurut Sang Motivator dan Terapis Berpikir Positif Dr. Ibrahim Elfiky menjelaskan dalam bukunya yang berjudul Terapi Berpikir Positif bahwa perasaan bahwa pikiran melahirkan mindset, Pikiran mempengaruhi intelektual, fisik dan perasaan. Hal inilah yang mendasari kenapa kita harus bisa memanage emosi agar kita bahagia. Solusi yang kami akan tawarkan adalah penyuluhan dan edukasi dengan pendekatan psikologis terhadap pendidik, terutma orang tua siswa kelas IV SDN Cipasung Kec. Darma Kab. Kuningan sebagai pendidik utama agar bisa mengelola emosi untuk bisa berpikir positif dan menemukan perasaan bahagia. Didalam penyuluhan tersebut kami akan menjelaskan secara detail tentang hakekat peran orang tua dalam pengasuhan dan pendidikan dari sisi psikologis dan agama. Bukan hanya ranah praktis tentang pendidikan, tapi juga tentang pengelolaan emosi yang tidak akan berdampak buruk terhadap perkembangan mental anak.

\section{METODE PELAKSANAAN}

Sebelum dilakukan penyuluhan, kami Tim Dosen berkunjung terlebih dahulu ke SDN Cipasung guna melakukan observasi dan wawancara mandiri untuk mengetahui kendala apa yang dihadapi Sekolah selama masa Pandemi Covid 19. Atas permintaan pihak Sekolah yang disampaikan oleh Kepala Sekolah kami akan sepakat untuk melakukan penyuluhan guna mengedukasi para orang tua dalam mendampingi pembelajaran daring siswa di rumah yang sejauh ini merasa kesulitan. Adapun acara penyuluhan yang akan dilaksakan tersusun sebagai berikut:

1. Penyuluhan dipaparkan oleh Tim Dosen kepada Staf Pengajar dan Kepala Sekolah SDN Cipasung.

2. Materi Pertama dan Kedua Disajikan Oleh Tim Dosen di Akhiri dengan Diskusi dan tanya jawab.

3. Penyuluhan akan dipaparkan oleh Tim Dosen kepada orang tua dari siswa SDN Cipasung (atau yang mewakili).

4. Materi Pertama dan Kedua Disajikan Oleh Tim Dosen di Akhiri dengan Diskusi dan tanya jawab.

5. TIM Dosen berdiskusi untuk kelanjutan program pengabdian masyarakat dan cara evaluasinya.

6. TIM dosen meminta Guru, kepala sekolah dan komite sekolah untuk mengevaluasi hasil penyuluhan dengan membagikan angket yang akan dibagikan setelah selesai penyuluhan.

Instrumen yang digunakan dalam penelitian ini menggunakan data survey. Adapun surveynya dalam bentuk angket/kuesioner terbuka. Sementara itu, teknik analisis 
data pada penelitian ini dilakukan dengan menghitung angket terbuka dengan presentase. Kemudian hasil perhitungan, menjadi dasar dalam menganalisis dan menyimpulkan bagaimana kondisi orang tua yang hadir di SDN Cipasung.

\section{HASIL DAN PEMBAHASAN}

Pelaksanaan penyuluhan dan workshop yang diadakan di SDN Cipasung Kec. Darma Kab. Kuningan bisambut dengan orang tua wali kelas IV dengan antusias. Orang tua berdatangan sebelum acara dimulai. Sebelum masuk ke ruangan orang tua melakukan prosesur protokol kesehatan yang kami terapkan, yaitu mencuci tangan dan cek suhu. Jika kondisi orang tua terdeteksi baik, dilanjutkan dengan mengisi daftar hadir yang telah disediakan. Di dalam ruangan, protokol kesehatan tetap dilaksanakan dengan ketat dengan tempat duduk yang berjarak dan menggunakan masker. Kegiatan awal diisi dengan pembukaan, dilanjutkan dengan sambutan oleh pihak sekolah yang diwakili oleh wali kelas, kelas IV. Kegiatan inti berlanjut dengan materi menjadi ibu bahagia. Para orang tua yang mayoritas diwakili oleh ibu menyimak dengan seksama materi yang dijelaskan oleh narasumber. Dipertengahan sesi, narasumber membimbing orang tua untuk lelakukan healing dengan metode Tehnik Hand Cataleptic untuk melepaskan emosi-emosi negatif yang ada dalam diri, yang sebelumnya telah ditulisakn terlebih dahulu di awal sesi penyajian materi. Pelaksanaan workshop berjalan dengan riang gembira, karena dalam materi yang disajikan ada beberapa intruksi yang mengharuskan orang tua membayangkan kondisi bahagia di masa kanak- kanak.

Diakhir kegiatan, orang tua mengungkapkan terima kasih dan mengungkapkan kebahagian mereka yang telah menirima banyak informasi yang sebelumnya belum mereka ketahui. Orang tua tergugah untuk menjadi orang tua yang lebih perhatian dan penyayang. Dari materi materi yang disampaikan ada juga tentang sejarah istri nabi, yang menginspirasi para ibu untuk menjadi istri yang tangguh.

Kemudian hasil analisis angket yang disebar setelah kegiatan dapat dilihat pada tabel 1:

Tabel 1. Hasil Analisis Angket Menjadi Ibu Bahagia

\begin{tabular}{|c|c|c|c|}
\hline \multirow{2}{*}{ No. } & \multirow{2}{*}{ PERNYATAAN } & \multicolumn{2}{|c|}{ \% JAWABAN } \\
\hline & & YA & TIDAK \\
\hline 1. & Sudahkah anda menjadi ibu yang bahagia? & 100 & 0 \\
\hline 2. & $\begin{array}{l}\text { Apakah dalam menjalankan tugas sebagai seorang ibu } \\
\text { anda dipengaruhi oleh suasana hati }(\text { mood }) \text { ? }\end{array}$ & 80,95 & 19,05 \\
\hline 3. & $\begin{array}{l}\text { Apakah anda punya waktu untuk diri sendiri dalam } \\
\text { satu minggu? }\end{array}$ & 47,62 & 52,38 \\
\hline 4. & $\begin{array}{l}\text { Begitu banyak pekerjaan yang harus dilakukan. } \\
\text { Sudahkan anda menyusun skala prioritas pekerjan? }\end{array}$ & 66,67 & 33,33 \\
\hline 5. & Apakah anda menikmati peran sebagai seorang ibu? & 100,00 & 0,00 \\
\hline 6. & $\begin{array}{l}\text { Apakah anda masih punya waktu untuk menjaga } \\
\text { kecantikan dan penampilan ditengah kesibukan sebagai } \\
\text { ibu? }\end{array}$ & 66,67 & 33,33 \\
\hline 7. & Apakah anda sering berkata buruk kepada anak anda? & 19,05 & 80,95 \\
\hline 8. & Apakah anda sering memuji anak anda? & 80,95 & 19,05 \\
\hline 9. & Sudahkah anda bersyukur menjadi seorang ibu? & 100,00 & 0,00 \\
\hline 10. & $\begin{array}{l}\text { Apakah anda punya waktu kebersamaan dengan anak } \\
\text { meskipun saat bersamaan anda sibuk bekerja? }\end{array}$ & 90,48 & 9,52 \\
\hline
\end{tabular}


Dari data dari tabel tersebut bisa terlihat bahwa seluruh orang tua yang hadir dalam kondisi bahagia. Namun mereka mengakui bahwa dalam mengurus rumah dan mendidik anak, seringkali mereka dipengaruhi oleh Mood nya. Banyak orang tua yang tidak mempunyai waktu untuk me time, dan hanya sibuk mengurusi rumah dan anak. Padahal waktu me time, sangat diperlukan oleh Ibu untuk beristirahat dari rutinitas.Ibuibu menganggap anak dan urusan adalah prioritas mereka, sehingga urusan tentang hal tersebut selalu diutamakan dibanding urusan pribadinya. Mereka menikmati peran mereka sebagai orang tua.

Sebagian besar Ibu tetap memperhatikan penampilan mereka secara fisik, namun tidak sedikit juga yang cuek. Kesibukan fisik orang tua membuat mereka lelah secara psikis, sehingga tidak bisa mengontrol diri. Hal tersebut menyebabkan ada beberapa orang tua yang kerap mengeluarkan kata- kata kasar kepada anaknya. Namun dalam kondisi tertentu, kebanyakan orang tua tetap melakukan pujian terhadap anaknya jika perlu apresiasi. Secara keseluruhan, orang tua tetap bersyukur atas apa yang telah mereka miliki dengan segala dinamika yang dihadapinya. Hal ini terbukti walaupun orang tua sibuk, kebanyakan dari mereka tetap punya waktu untuk membersamai anak mereka.

Dokumentasi dalam proses kegiatan:

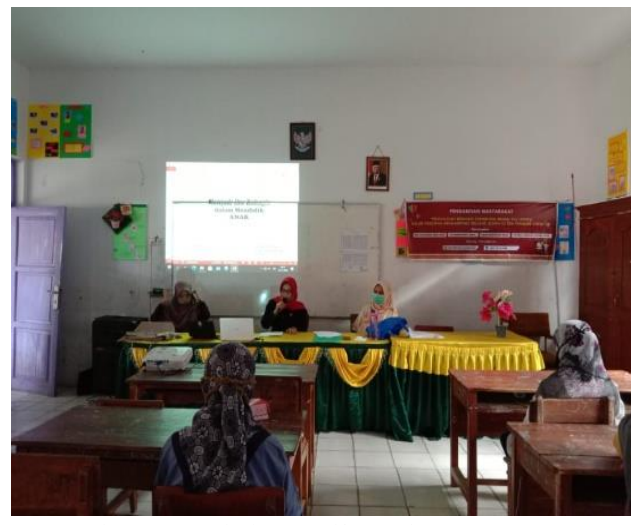

Sambutan Oleh Wali Kelas

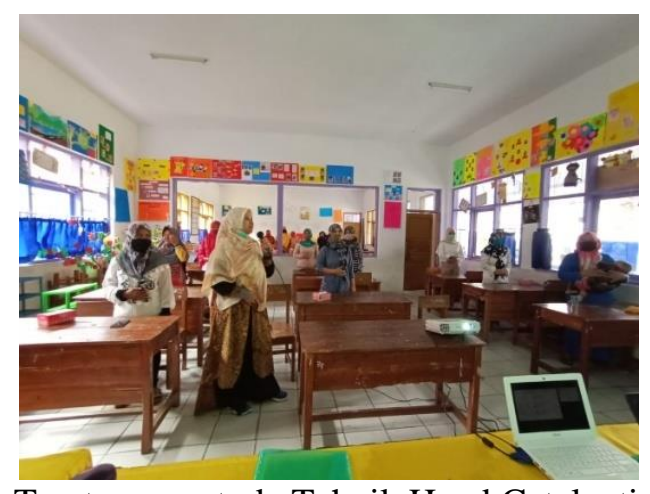

Treatmen metode Tehnik Hand Cataleptic

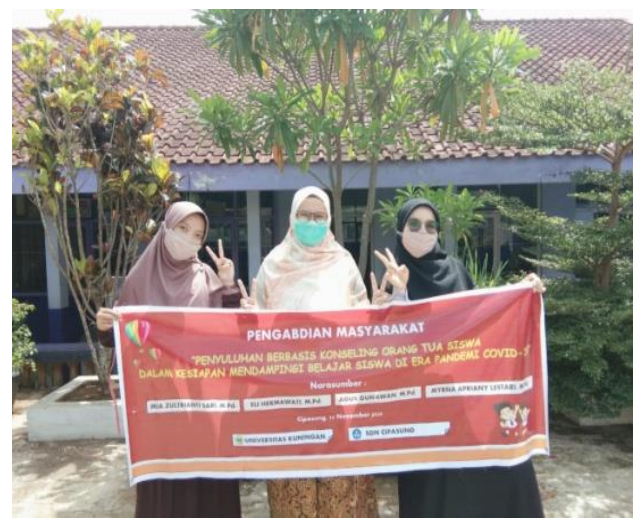

Tim Ketua dan Anggota

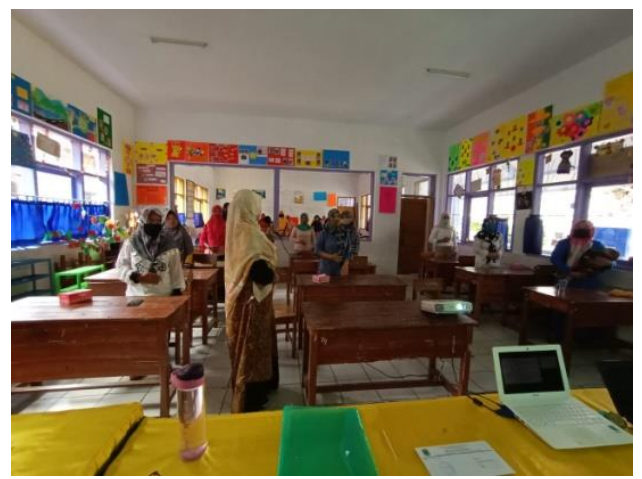

Pelaksanaan Workshop 


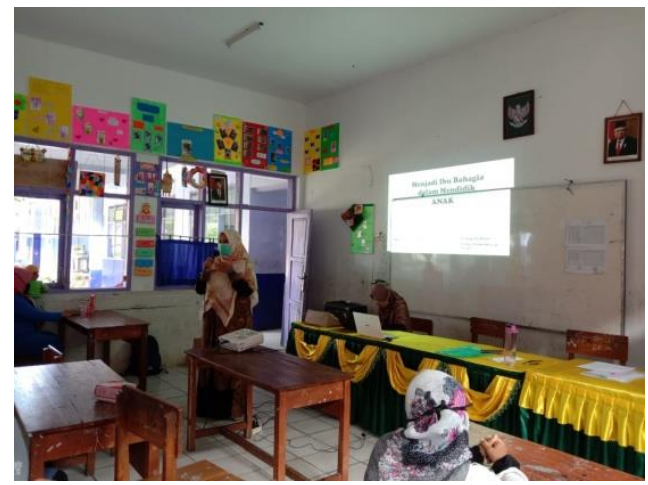

Evaluasi

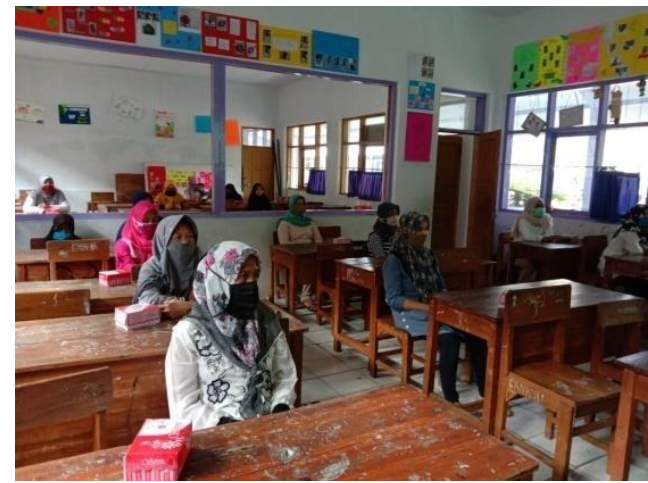

Peserta Workshop

\section{SIMPULAN}

Sebagai orang tua mereka mempunyai peran penting dalam keberhasilan perkembangan pendidikan peserta didik. Edukasi kepada orang tua membuat mereka jauh lebih siap untuk mendampingi proses belajar peserta didik dirumah, terutama saat pandemi covid 19. Dengan ilmu yang memadai, orang tua tidak akan melakukan banyak kesalahan yang akan berdampak negatif kepada anak. Orang tua bersukur dan bahagia menjalani peran yang dijalaninya, namun tetap pernah melakukan hal- hal yang seharusnya dalam pengasuhan tidak perlu terjadi. Dengan ilmu yang telah didapat, orang tua menjadi lebih teredukasi untuk pengasuhan. Orang tua akan menjadi partner yang bai bagi guru dan sekolah di masa pandemi covid 19.

\section{SARAN}

Orang tua mempunyai waktu untuk mencari ilmu tentang pengasuhan sehingga lebih siap dalam mendidik dan membersamai anak. Pihak sekolah lebih banyak mengadakan waktu untuk bermusyawarah dengan orang tua dan memeberikan edukasi yang tepat kepada orang tua, karena kebanyakan dari orang tua belum terbiasa untuk mengajarkan anak- anak merka di rumah. Terlebih lagi, tidak semua orang tua mempunyai tarap keilmuan yang sama seperti guru di Sekolah.

\section{UCAPAN TERIMA KASIH}

Terima Kasih kepada Universitas Kuningan, yang di jembatani oleh LPPM yang telah mendukung secara nyata kepada dosen untuk melakukan Tridarma Pengabdian Masyarakat dengan memberikan biaya untuk terlaksananya Pengabdian di Masyarakat. Ucapan terima kasih yang selnjutnya kepada Guru dan Kepala Sekolah atas kesediaan dan kerjasama yang telah mengundang para orang tua siswa kelas IV untuk menerima konseling dari kami. Semoga apa yang telah kita laksanakan menjadi amal kebaikan dan berbuah manfaat untuk orang banyak.

\section{DAFTAR PUSTAKA}

Borup, J. (2016). Teacher perceptions of parental engagement at a cyber high school. Journal of Research on Technology in Education Preservice Teachers, 48(2), 6783. 
Buthaina, A.-B., \& Mohamed, E. M. (2020). The Impact of COVID-19 on Children Parent's Perspective Although. International Journal of Nutrition, Pharmacology, Neurological Diseases |, 10(3), 164-165. https://doi.org/10.4103/ijnpnd.ijnpnd

Desmita. (2009). Psikologi Perkembangan Peserta Didik. Bandung: PT Remaja Rosdakarya.

Kidd, W., \& Murray, J. (2020). The Covid-19 pandemic and its effects on teacher education in England: how teacher educators moved practicum learning online. European Journal of Teacher Education, 43(4), 542-558. https://doi.org/10.1080/02619768.2020.1820480

Lapada, A. A., Miguel, F. F., Robledo, D. A. R., \& Alam, Z. F. (2020). Teachers' Covid19 Awareness, Distance Learning Education Experiences and Perceptions towards Institutional Readiness and Challenges. International Journal of Learning, Teaching and Educational Research, 19(6), 127-144. https://doi.org/10.26803/ijlter.19.6.8

Nauli Thaib, E. (2013). Hubungan Antara Prestasi Belajar Dengan Kecerdasan Emosional. Jurnal Ilmiah Didaktika, 13(2), 384-399. https://doi.org/10.22373/jid.v13i2.485

Purwanto, A., Pramono, R., Asbari, M., Santoso, Priyono Budi Wijayanti, Laksmi Mayesti Hyun, C. C., \& Putri, R. S. (2019). Studi Eksploratif Dampak Pandemi COVID-19 Terhadap Proses Pembelajaran Online di Sekolah Dasar. Journal of Education, Psychologyy and Counseling, 15(2), 98-112. http://journal.unas.ac.id/oikonamia/article/view/748/620

Rosni, R. (2017). Analisis Tingkat Kesejahteraan Masyarakat Nelayan Di Desa Dahari Selebar Kecamatan Talawi Kabupaten Batubara. Jurnal Geografi, 9(1), 53. https://doi.org/10.24114/jg.v9i1.6038

Rusmiati, A. R., Reza, R., Achmad, S., Syaodih, E., Nurtanto, M., Sultan, A., Riana, A., \& Tambunan, S. (2020). The Perceptions of Primary School Teachers of Online Learning during the COVID-19 Pandemic Period: A Case Study in Indonesia. Journal of Ethnic and Cultural Studies, 7(2), 90-109.

Silaen, A. C., \& Dewi, K. S. (2015). Meningkatkan regulasi emosi siswa melalui layanan bimbingan kelompok dengan teknik sosiodrama. Jurnal Empati, 4(April), 175-181.

Syah, M. (2010). Psikologi Pendidikan dengan pendekatan baru. Remaja Rosdakarya.

Syamsuddin, A. (2007). Psikologi Kependidikan. Bandung: PT Remaja Rosdakarya.

Telaumbanua, M., \& Nugraheni, M. (2018). Peran Ibu Rumah Tangga Dalam Meningkatkan Kesejahteraan Keluarga. Sosio Informa, 4(2), 418-436. https://doi.org/10.33007/inf.v4i2.1474

Trentacosta, C. J., Izard, C. E., Mostow, A. J., \& Fine, S. E. (2006). Children's emotional competence and attentional competence in early elementary school. School Psychology Quarterly, 21(2), 148-170. https://doi.org/10.1521/scpq.2006.21.2.148 